\title{
One Step Photopolymerization of N, N-Methylene Diacrylamide and Photocuring of Carboxymethyl Starch-Silver Nanoparticles onto Cotton Fabrics for Durable Antibacterial Finishing
}

\author{
M. A. El-Sheikh and H. M. Ibrahim \\ Textile Research Division, National Research Centre, El-Behooth Street, Dokki, Giza, P.O. Box 12311, Egypt \\ Correspondence should be addressed to M. A. El-Sheikh; dr.manal.elsheikh@gmail.com
}

Received 7 February 2014; Revised 14 June 2014; Accepted 5 July 2014; Published 17 July 2014

Academic Editor: John F. Kennedy

Copyright (C) 2014 M. A. El-Sheikh and H. M. Ibrahim. This is an open access article distributed under the Creative Commons Attribution License, which permits unrestricted use, distribution, and reproduction in any medium, provided the original work is properly cited.

\begin{abstract}
The PI/UV system ((4-trimethyl ammonium methyl) benzophenone chloride/UV) was used to synthesize carboxymethyl starch(CMS-) stabilized silver nanoparticles (AgNPs). AgNPs so prepared had round shape morphology with size of 1-7 nm. The prepared AgNPs were utilized to impart antibacterial finishing for cotton fabrics. The PI/UV system was further utilized to fix AgNPs onto cotton fabrics by photocrosslinking of AgNPs-CMS composite onto cotton fabrics to impart durable antibacterial properties. Effect of irradiation time and incorporating $\mathrm{N}, \mathrm{N}$-methylene diacrylamide (MDA) in different concentrations on antibacterial performance before and after repeated washing cycles was studied. S. aureus and E. coli were used to evaluate the antibacterial performance of finished fabrics. The antibacterial performance was directly proportional to the irradiation time and concentration of MDA but inversely proportional to the number of washing cycles. The inhibition zone of $S$. aureus and $E$. coli is the same although they are different in the cell wall structure and mode of action due to the nanosize structure formed.
\end{abstract}

\section{Introduction}

Metal nanoparticles can be prepared and stabilized by physical and chemical methods; the chemical approach, such as chemical reduction, electrochemical techniques, and photochemical reduction, is most widely used $[1,2]$. In the global efforts to reduce generated hazardous waste, "green" synthesis of AgNPs is progressively integrating with modern developments in science and industry. This "green" synthesis is geared to guide in minimizing the use of unsafe reactants and maximizing the efficiency of synthesis process. AgNPs were green synthesized using different techniques [3-13]. Direct photoreduction and photosensitization are powerful approaches for the in situ synthesis in polymer matrixes [14-22]. The heart of the photochemical approach is the generation of $\mathrm{M}^{0}$ in such conditions that their precipitation is thwarted. $\mathrm{Ag}^{0}$ can be formed through direct photoreduction of a silver source or reduction of silver ions using photochemically generated intermediates, such as radicals. The key step of the process is the reaction of silver cations with photogenerated transient species that are able to reduce them to silver metal atoms. Two classes of photoinduced reactions were used to produce these primary radicals. The first is based on the reaction of an electron rich molecule (ether, thiol, amine, ...) with the highly oxidant triplet state of a sensitizer excited upon absorption of the actinic photons. The second involves the direct hemolytic photocleavage of a sigma bond [23].

It is well known that silver exhibits effective antibacterial properties with low toxicity for humans and animals compared with other heavy metals [24, 25]. Silver and silver compounds are effective for both Gram -ve and Gram +ve bacteria, whereas the efficacy of conventional antibiotics varies with the species of bacteria [25]. Silver is a safer antibacterial agent compared with some possible organic antibacterial ones that have been avoided because of the risk of their harmful effects on the human body. Silver has been described as being "oligodynamic" because of its 
ability to exert a bactericidal effect on products containing silver, principally due to its antimicrobial activities and low toxicity to human cells [26-29]. Its therapeutic property has been proven against a broad range of microorganisms, over 650 disease-causing organisms in the body, even at low concentrations [30-32]. AgNPs are a nontoxic and nontolerant disinfectant [33]. Using AgNPs leads to increasing the number of particles per unit area and thus antibacterial effects can be maximized [34].

Textile products have been widely used in medicine, hygiene, and health [35]. Hygienic and health textiles have been used in large quantities in places such as hospitals and theaters, where contact with the skin of the users occurs repeatedly and frequently. It is desirable, for the reason of health, that these textile materials should have higher antibacterial activity. Selection of an antimicrobial agent depends on several criteria, such as the mechanism of antimicrobial activity, its effectiveness for bacteria and fungi, toxicity, application method, washing fastness, and cost.

Cotton may act as a nutrient and become a suitable medium for bacterial growth $[36,37]$. Therefore, cotton fibers are treated with numerous chemicals to get better antimicrobial textiles [38-41]. Among the various antimicrobial agents, AgNPs show strong inhibitory and antibacterial effects [37, 42]. Application of AgNPs on cotton due to its outstanding features has developed in recent years [5, 10, 37, 43-58].

Normally, there is no attraction between inorganic particles and polymeric materials such as textiles [30]. The difference between surface energy of the two aforementioned organic and inorganic materials causes a kind of repellency in their interfaces [59]. This problem is intensified by using NPs because of their high specific surfaces. Consequently, surface modification of textiles with NPs is not permanent, especially against washing.

Most presented methods for stabilizing inorganic nanostructured materials on the textile surfaces need several steps of preparation, functionalization, final treatment, drying, curing, and so on. These steps are expensive and very time consuming for high-scale manufacturing production. Using different binders such as acrylic binder [60] and Printofix Binder MTB EG liquid [49] for fixation of metal NPs on cotton fabrics was applied. The use of crosslinking agents such as polysiloxane [61] and 1,2,3,4-butanetetracarboxylic acid [44] to stabilize AgNPs on cotton fabric has been also studied. In situ synthesis of AgNPs on cotton fabric using Tollens' reagent [43] and within chitosan-attached cotton fabric [46] was also used. These techniques enable considerable improvements in the performance and durability of finished cotton fabrics.

With the development of water soluble efficient photosensitizers for polymerization reactions, attention has been given to grafting reactions in largely aqueous media, involving hydrophilic substrates. El-Sheikh [62-64] used a water soluble photosensitizer 4-(trimethyl ammoniummethyl) benzophenone chloride/UV system to initiate graft copolymerization of acrylic acid or acrylamide onto native starch and CMS with an effective graft yield. Recently, El-Sheikh [22] used 4-(trimethyl ammoniummethyl) benzophenone chloride/UV system, for the first time, to synthesize AgNPs. El-Sheikh et al. [65] further utilized the same system to perform durable antibacterial finishing to wool and acrylic fabrics via photocuring of the AgNPs treated fabric.

In this work, AgNPs-CMS prepared according to a reported method [22] was used to impart antibacterial finishing to cotton fabrics via pad-dry-photocure process in presence and in absence of MDA. MDA was photopolymerized onto AgNPs-CMS-cotton fabric composite using PI/UV system to crosslink AgNPs-CMS film onto the surface of cotton fabrics. This process aims at fixing AgNPs on the surface of cotton fabrics, consequently increases the durability of the AgNPs finished cotton fabrics. The photosynthesis of AgNPs, the photopolymerization of MDA, and the photocuring of the AgNPs-CMS-cotton fabric composite are all performed at mild temperature without using any solvents or hazardous chemicals. The whole process could be described as a "green, safe, and easy" process. Effect of irradiation time and incorporating MDA in different concentrations on antibacterial performance before and after repeated washing cycles was studied. The synthesized AgNPs were assessed by measuring the absorbance, the size, the shape, and the particle size distribution histogram of the colloidal solution. The durability of the cotton fabrics finished against bacterial activity was tested by performing the antibacterial activity of the AgNPs treated cotton fabrics towards Gram +ve and Gram -ve bacteria before and after repeated washing cycles $(1,3,5,7,10,15$, and 20 cycles $)$.

\section{Experimental}

2.1. Materials. A $100 \%$ scoured and bleached cotton fabric was supplied by Misr El-Beida Dyers, Egypt. The fabric was not subjected to any type of finishing treatments. The fabric was washed with a solution containing $5 \mathrm{~g} / \mathrm{L}$ sodium carbonate and $5 \mathrm{~g} / \mathrm{L}$ nonionic detergent at boil for 3 hours. It was then rinsed with hot and cold water and left to dry in air at room temperature.

Native maize starch (St.) was kindly supplied by the Egyptian Company for Starch and Glucose Manufacture, Cairo, Egypt.

4-(Trimethyl ammoniummethyl) benzophenone chloride was supplied by "The Associated Octel Ltd., Widnes, Great Britain," and used without further purification.

Egyptol, a nonionic detergent, was provided by The Egyptian Company for Starch, Yeast and Detergents, Alexandria, Egypt.

Monochloroacetic acid, sodium hydroxide, sodium carbonate, silver nitrate, MDA, hydrochloric acid, acetic acid, ethanol, and isopropanol were laboratory grade chemicals.

2.2. Instrumentation. The irradiation reaction vessel consists of a quick fit water-cooled $125 \mathrm{~W}$ medium-pressure $\mathrm{Hg}$ lamp assembly as a UV irradiation source immersed in a quick fit $150 \mathrm{~mL}$ cylindrical tube. The total dose of the UV irradiation was controlled by controlling the time of exposure, that is, the reaction time. The reaction temperature was controlled using a thermostatic water bath. 


\subsection{Method}

2.3.1. Carboxymethylation. Water soluble carboxymethyl starch with DS $=0.2$ was prepared according to a reported method [66]. In this method, $100 \mathrm{~g}$ of maize starch was placed in a sealable bottle and mixed together with a known volume of isopropanol. An aqueous solution of sodium hydroxide $(0.5 \mathrm{~mole} / \mathrm{mole} \mathrm{St}$.) was added dropwise to the starch-isopropanol mixture under stirring until the whole amount of sodium hydroxide was added. The sodium salt solution of monochloroacetic acid $(0.2 \mathrm{~mole} / \mathrm{mole} \mathrm{St}$.$) ,$ prepared by the reaction of monochloroacetic acid with the equivalent amount of sodium carbonate, was added dropwise to the starch-isopropanol-sodium hydroxide mixture under continuous stirring until complete addition of the sodium monochloroacetate solution. Stirring was then stopped and the bottle was closed and kept at $30^{\circ} \mathrm{C}$ for 24 hours. After carboxymethylation, the CMS samples were washed with ethanol:water solution $(80: 20)$ while excess alkali was neutralized using acetic acid. After washing, the CMS samples were filtered and oven dried at $70^{\circ} \mathrm{C}$.

2.3.2. Preparation of AgNPs. AgNPs (particle size 1-7 nm) were prepared by photoreduction of silver nitrate using 4(trimethyl ammoniummethyl) benzophenone chloride/UV system according to a reported method [22]. The optimum conditions of the photosynthesis of AgNPs obtained from this method were applied on a larger scale to prepare AgNPs "stock colloidal solution" sample sufficient for finishing different textile fabrics to impart them antibacterial properties. According to the method in [22], a known weight of CMS $(10 \mathrm{~g} / \mathrm{L})$ was stirred in a known volume of distilled water (material: liquor ratio 1:20) in a beaker using a mechanical stirrer. After complete dissolution of CMS, an aqueous solution of 4-(trimethyl ammoniummethyl) benzophenone chloride $(1 \mathrm{~g} / \mathrm{L})$ was added to the CMS solution followed by adding silver nitrate solution $(1 \mathrm{~g} / \mathrm{L})$ under continuous stirring until complete mixing of the whole contents. The $\mathrm{pH}$ was finally adjusted to 7. Doing so, the beaker contents were poured in the irradiation tube and transferred to a thermostatic water bath with a magnetic stirrer. The UV lamp is now immersed in the solution to just above the bottom of the tube to allow the magnet to move and to allow the whole solution to be exposed to the UV irradiation. The temperature was then allowed to rise gradually until the required temperature $\left(40^{\circ} \mathrm{C}\right)$ is reached. Finally, the UV lamp is switched on and the whole contents were kept at the synthesis temperature for 60 min under continuous stirring. After synthesis, the yellowish brown colloidal solution is kept in a sealable bottle at room temperature $\left(25^{\circ} \mathrm{C}\right)$.

2.3.3. Antibacterial Finishing. Finishing procedure was applied to cotton fabrics using a pad-dry-photocure technique. The cotton fabrics were treated with the obtained colloidal AgNPs solution at room temperature. The finishing bath contains the synthesized AgNPs alone or AgNPs and MDA. Fabrics were padded in the treating solutions, squeezed to wet pickup of about $100 \%$, dried at $100^{\circ} \mathrm{C}$ for
$5 \mathrm{~min}$, and photocured at room temperature. The dimensions of the cotton fabric were about $30 \mathrm{~cm} \times 17 \mathrm{~cm}$, suitable for the area of exposure to the UV lamp.

2.3.4. Photocuring of AgNPs Finished Cotton Fabrics. AgNPs finished cotton fabrics in absence and in presence of different concentrations $(5,10$, and $15 \mathrm{~g} / \mathrm{L})$ of crosslinking agent (MDA) were photocured at room temperature $\left(25^{\circ} \mathrm{C}\right)$ using the water-cooled $125 \mathrm{~W}$ medium-pressure Hg lamp assembly as a UV irradiation source for different irradiation durations $(15,30$, and $60 \mathrm{~min})$. The finished samples were washed in an aqueous solution of fabric: liquor 1:10 containing $2 \mathrm{~g} / \mathrm{L}$ Egyptol at $50^{\circ} \mathrm{C}$ for $10 \mathrm{~min}$ to remove the unreacted MBA and the unfixed AgNPs. Finally the samples were washed with cold water and dried at ambient condition.

2.4. Characterizations and Analyses. The DS of the carboxymethylated starch samples was determined via determination of the carboxyl content according to a reported method [67].

The UV-vis spectra of AgNPs and 4-(trimethyl ammoniummethyl) benzophenone chloride were recorded using UV-2401, UV-vis Spectrophotometer, Shimadzu, Japan, at wavelength range from 190 to $550 \mathrm{~nm}$. $\lambda \max$ at $256 \mathrm{~nm}$ is characteristic to 4-(trimethyl ammoniummethyl) benzophenone chloride whereas $\lambda \max$ at $390-420$ is characteristic to AgNPs. Synthesis of AgNPs is expressed as absorbance of the colloidal solution of the samples under test. The absorbance, the broadening, and the wavelength of the band measure the intensity of the colloidal solution, that is, the conversion of silver ions to AgNPs. Very concentrated AgNPs samples did not show one smooth band (either sharp or broad) but showed a number of crowded sharp bands. This behavior leads to false readings. So, concentrated samples which showed this behavior were diluted " $x$ " times and the obtained absorbance value was then multiplied by " $x$ " to obtain the actual absorbance value. The accuracy of this dilution technique was tested by comparing the absorbance readings of certain samples with moderate concentration before and after dilution. The readings were found approximately the same after multiplying by " $x$ " times of dilutions.

Transmission electron microscope was used to characterize AgNPs. Thus, the shape and size of the synthesized silver nanoparticles were characterized by means of a JEOLJEM1200 transmission electron microscope. The samples were prepared by placing a drop of the colloidal solution on a 400-mesh copper grid coated by an amorphous carbon film and evaporating the solvent in air at room temperature. The average diameter of the silver nanoparticles was determined from the diameter of nanoparticles found in several chosen areas in enlarged microphotographs. The particle size was measured from the TEM image using the software "Revolution vl.6.0b195," a simple electron microscope tool for acquiring images, maps, and spectra using the Spectral Engine, 1999-2002 4pi analysis, Inc.

Durability of the treated cotton fabrics against bacterial activity was obtained by performing the antibacterial activity of the AgNPs untreated and AgNPs treated cotton fabrics 
before and after repeated washing cycles $(1,3,5,7,10,15$, and 20 cycles). Each washing cycle was performed by washing the finished samples in an aqueous solution of fabric : liquor ratio $1: 10$ containing $2 \mathrm{~g} / \mathrm{L}$ Egyptol at $50^{\circ} \mathrm{C}$ for $10 \mathrm{~min}$ then washing the samples with cold water and drying at ambient condition.

\subsection{Evaluation of Antibacterial Activity}

2.5.1. Materials. Two bacterial strains from the Faculty of Women for Art, Science and Education, Ain Shams University, Cairo, Egypt, were employed. These include Staphylococcus aureus (S. aureus) as Gram +ve bacteria and Escherichia coli (E. coli) as Gram -ve bacteria and they were selected as test cells because they are the most frequent bacteria in the wound infection to represent Gram +ve and Gram -ve bacteria, respectively. Fresh inoculants for antibacterial assessment were prepared on nutrient broth at $37^{\circ} \mathrm{C}$ for 24 hours.

2.5.2. Test Method. The antibacterial spectrum of the samples was determined against the test bacteria by disk diffusion method on an agar plate [68]. Five discs were obtained at different locations of the finished fabric. The final value of the inhibition zone was the mean of the inhibition zone values of the discs under test.

Although the time-kill kinetics gives a good overview on how fast an antimicrobial drug can kill certain bacteria and prevent their regrowth and although these parameters are important for the assessment of the efficacy of bactericidal drugs, this test is not performed for the current research work for the following reasons. The time-kill kinetics is performed along 24 hours and the susceptibility of disk diffusion test of antibacterial is measured each two hrs but the reading is not reported in these testes before 18 hrs. The detection reading time is $24 \mathrm{hrs}$ as shown in the disk diffusion method. So, the detection time is at $24 \mathrm{hrs}$ as shown in standard method $[69,70]$. In the current work, disk diffusion test standard method was used. The inhibition at $24 \mathrm{hrs}$ gives the same result as the time-kill kinetics. The aim of this research work is to show the effects of concentration of AgNPs on the finished fabrics and the effect of photocuring time on the durability of finished fabrics rather than the effect of the time of killing of the fabrics. The fabrics here act as an antibacterial agent rather than an antibiotic. That is why there was no need to perform the time-kill kinetics. It is, then, sufficient to measure the inhibition zone after $24 \mathrm{hrs}$.

\section{Results and Discussions}

3.1. Photosynthesis of AgNPs. Figure 1 Shows the UV-vis spectrum (a), TEM micrograph (b), and particle size distribution histogram (c) of the photosynthesized AgNPs when CMS with DS $=0.2 ;[\mathrm{CMS}], 10 \mathrm{~g} / \mathrm{L} ;[\mathrm{PI}], 1 \mathrm{~g} / \mathrm{L} ;\left[\mathrm{AgNO}_{3}\right]$, $1 \mathrm{~g} / \mathrm{L}$; temperature, $40^{\circ} \mathrm{C}$; time, $60 \mathrm{~min} ; \mathrm{M}: \mathrm{L}$ ratio, $1: 20$; and $\mathrm{pH}, 7$ were used. A proposed mechanism of the photosynthesis of AgNPs using 4-(trimethyl ammoniummethyl) benzophenone chloride/UV system, silver nitrate, and CMS was reported [22]. Figure 1(a) shows an intensive band with ideal bell shapes and high absorbance values at $406 \mathrm{~nm}$. This indicates the formation of AgNPs [3, 4, 9, 71] and reflects the efficiency of the current system in synthesizing AgNPs at the synthesis conditions. The sharp band at $256 \mathrm{~nm}$ is representing the PI. The appearance of this band means that PI is not totally consumed in the photoinitiation process or it is regenerated from its radical according to its "life cycle" [22]. Figures 1(b) and 1(c) show the TEM micrograph and the particle size distribution histogram of the synthesized AgNPs, respectively. As clear from the figures, AgNPs have round shape morphology with mean particle sizes between 1 and $7 \mathrm{~nm}$. Highest count $\%$ was found for AgNPs with particle size of $1 \mathrm{~nm}$.

\subsection{Effect of Irradiation Time on the Durability of the Antibac-} terial Finishing. Durability of AgNPs finished cotton fabrics is one of the problems facing the producers of these finished fabrics. Here is a trial for making easier, faster, and less expensive method for fixing AgNPs on the surface of cotton fabrics.

Table 1 shows the effect of subjecting the AgNPs finished cotton fabrics to UV irradiation for different irradiation durations $(15,30$, and $60 \mathrm{~min})$ before and after repeated washing cycles $(1,3,5,7,10,15$, and 20 cycles) on the durability of the antibacterial finished cotton fabric, in other meaning on the extent of fixation of AgNPs to the cellulosic fabrics.

Table 1 depicts the effect of the irradiation time ( $\mathrm{min}$ ) on the inhibition zone $(\mathrm{mm})$ for the samples along with up to 20 washing cycles. Figure 2 shows the disc diffusion test for AgNPs finished cotton fabric sample. The sample (disc of $17 \mathrm{~mm}$ in diameter) is seen at the center of the figure; the clear ring around the sample is the area where the microorganisms are dead, and the remaining area is the zone where the microorganisms are growing (bactericidal effect). From the figure, zero inhibition zone indicates killing of the microorganisms that existed on the sample but did not affect those outside the sample (bacteriostatic effect). It can be deduced from Table 1 that the antibacterial performance of cotton fabrics finished with AgNPs improves with increasing the irradiation time from 0 to $60 \mathrm{~min}$. The least inhibition zones were found for the samples that were not irradiated by UV source while the highest antibacterial performance was obtained for the highest irradiation with UV source (60 min). Table 1 also indicates that antibacterial performance of cotton fabrics finished with AgNPs decreased by washing and the lowest one at the 7th washing cycle that found zero inhibition zone but still has "bacteriostatic effect" up to the 20th washing cycle, that is, the antibacterial performance, is directly proportional to the irradiation time but inversely proportional to the number of washing cycles. The inhibition zone for Gram (+ve) bacteria and Gram (-ve) is the same although they are different in the cell wall structure and mode of action due to the nanosize structure formed.

The enhancement in the antibacterial performance as a result of the increase in the irradiation time is mainly due to the favorable effect of irradiation time of the PI/UV system on the generation of $\mathrm{PI}^{\bullet}$ radicals which initiate the photocrosslinking between cellulose (cotton fabric) and AgNPsCMS composite. The PI remaining from the photosynthesis 


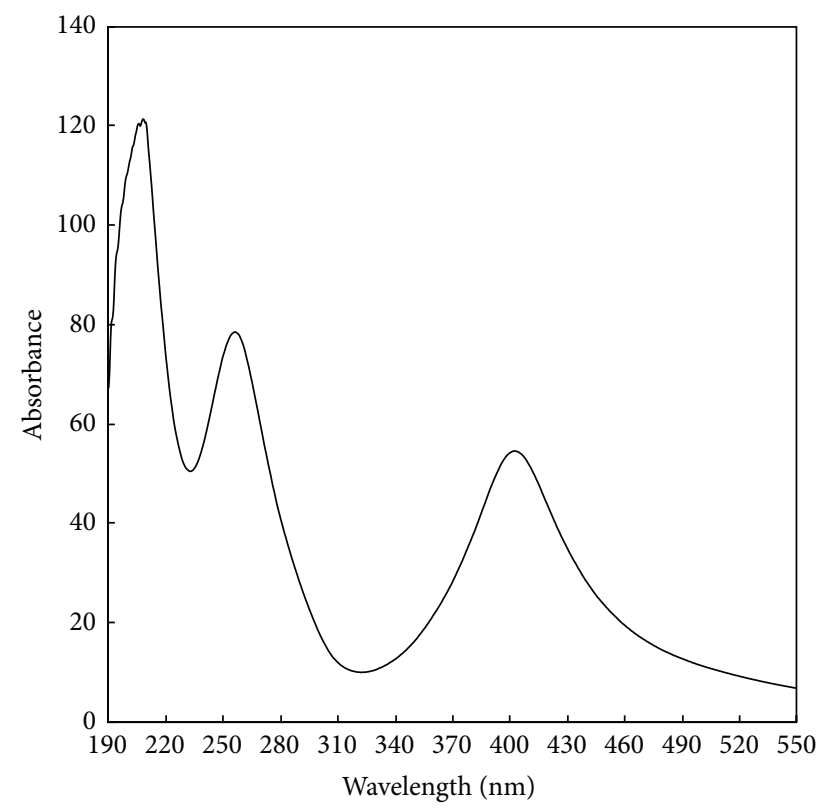

(a)

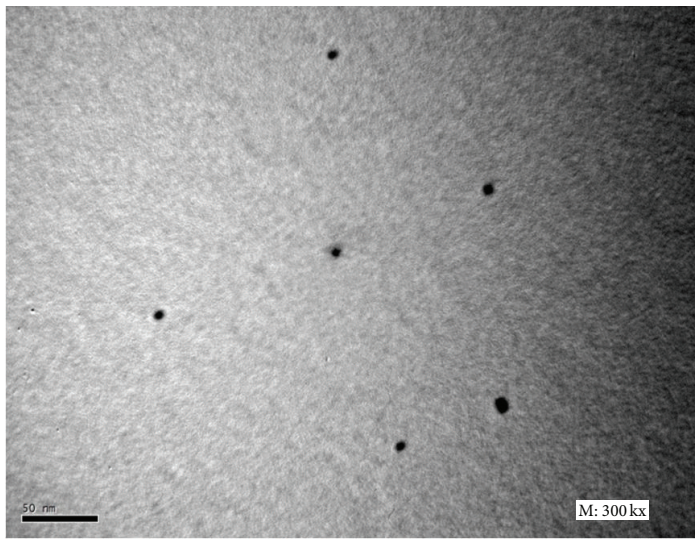

(b)

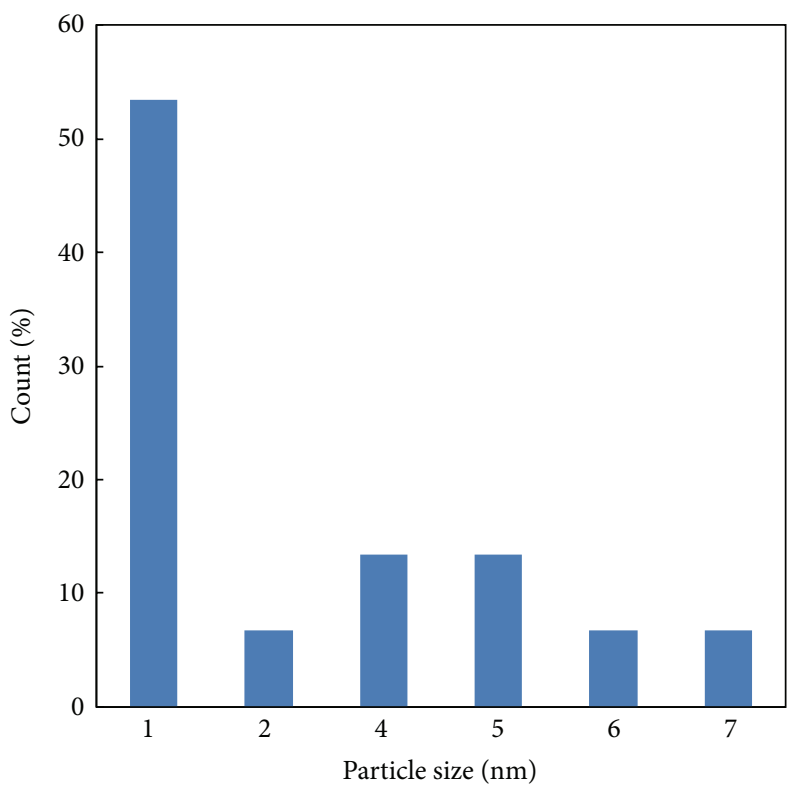

(c)

FIGURE 1: UV-vis spectrum, TEM micrograph, and particle size distribution histogram of the photosynthesized AgNPs. DS = 0.2; [CMS], $10 \mathrm{~g} / \mathrm{L} ;[\mathrm{PI}], 1 \mathrm{~g} / \mathrm{L} ;\left[\mathrm{AgNO}_{3}\right], 1 \mathrm{~g} / \mathrm{L}$; temperature, $40^{\circ} \mathrm{C}$; time, $60 \mathrm{~min} ; \mathrm{M}: \mathrm{L}$ ratio, $1: 20 ; \mathrm{pH}, 7$.

process, as clear from the band at $256 \mathrm{~nm}$ in Figure 1(a), was sufficient and capable of such a photocrosslinking process. In earlier work, Kumar and Singh [72] successfully obtained composite films prepared from aqueous dispersions of starch with microcrystalline cellulose using glycerol as plasticizer and irradiated under ultraviolet (UV) light using sodium benzoate as photosensitizer. In our work, photocrosslinking was achieved between cotton fabrics (sheet) and AgNPs-CMS composite (film) using 4-(trimethyl ammoniummethyl) benzophenone chloride under UV irradiation. The durability of the AgNPs finished cotton fabrics confirms the crosslinks between cotton fabric and AgNPs-CMS composite.

3.3. Effect of MDA Concentration on the Durability of the Antibacterial Finishing. Looking for better durability, MDA, crosslinking agent, was incorporated to the finishing bath in different concentrations $(5,10$, and $15 \mathrm{~g} / \mathrm{L})$ in order to evaluate its crosslinking effect on the durability of the antibacterial finished cotton fabrics. AgNPs finished cotton fabrics were 


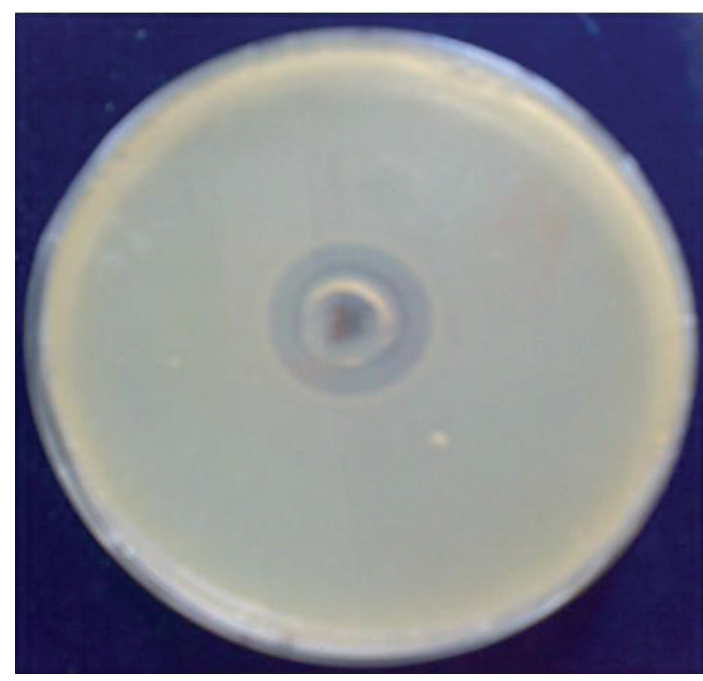

FIgURE 2: Inhibition zone of AgNPs finished cotton fabric.

subjected to UV irradiation for $60 \mathrm{~min}$ and tested for durability before and after repeated washing cycles $(1,3,5,7,10$, 15 , and 20 cycles).

Table 2 shows the effect of the MDA concentration on the durability of the antibacterial finishing up to 20 washing cycles. It can be deduced from Table 2 that the antibacterial performance of cotton fabrics finished with AgNPs increases by increasing the MDA concentration from 0 to $15 \mathrm{~g} / \mathrm{L}$. The least inhibition zones were found for the samples with zero MDA concentration while the highest antibacterial performance was obtained for the highest MDA concentration $(15 \mathrm{~g} / \mathrm{L})$. Table 1 also indicates that antibacterial performance of cotton fabrics finished with silver nanoparticles decreased by washing and the lowest one after the 10th washing cycle that found zero inhibition zone but still has "bacteriostatic effect" up to 20th time washing, that is, the antibacterial performance, is directly proportional to the concentration of MDA but inversely proportional to the number of washing cycles. The enhancement in the antibacterial performance as a result of the increase in the MDA concentration is expected. It is logic that increasing MDA, which is photopolymerized to poly-MDA under the effect of PI/UV system, increases the number of crosslinks responsible for the fixation of AgNPs-CMS composite onto the cotton fabrics. The more the concentration of MDA is the more the crosslinks obtained. It is important to remember that there is a considerable amount of PI remaining from the photosynthesis process, as clear from the band at $256 \mathrm{~nm}$ in Figure 1(a), which is sufficient and capable of photopolymerization and photocrosslinking processes.

By comparing results obtained from Table 1 and Table 2 one can find that either in presence or in absence of MDA the antibacterial performance of the finished fabrics showed "bacteriostatic effect" up to the 20th washing cycle. However, in presence of MDA, under identical conditions, the inhibition zones of the finished fabrics are, in general, higher than those of the finished fabrics in absence of MDA regardless of the number of washing cycles. At MDA with concentration
TABLE 1: Effect of irradiation time on the inhibition zone $(\mathrm{mm})$ of S. aureus and E. coli. Synthesis conditions: DS =0.2; [CMS], $10 \mathrm{~g} / \mathrm{L}$; [PI], $\left.1 \mathrm{~g} / \mathrm{L} ; \mathrm{AgNO}_{3}\right], 1 \mathrm{~g} / \mathrm{L}$; temperature, $40^{\circ} \mathrm{C}$; time, $60 \mathrm{~min} ; \mathrm{M}: \mathrm{L}$ ratio, $1: 20 ; \mathrm{pH}$, 7. Finishing conditions: pad-dry-photocure, AgNPs colloidal solution only. Curing conditions: drying for $5 \mathrm{~min}$ at $100^{\circ} \mathrm{C}$; UV curing for 15, 30, and $60 \mathrm{~min}$. Washing conditions: Egyptol, $2 \mathrm{~g} / \mathrm{L}$; fabric : liquor ratio, $1: 10$; temperature, $50^{\circ} \mathrm{C}$ for $10 \mathrm{~min}$.

\begin{tabular}{|c|c|c|c|}
\hline \multirow{2}{*}{$\begin{array}{l}\text { Irradiation time } \\
(\mathrm{min})\end{array}$} & \multirow{2}{*}{$\begin{array}{c}\text { Number of } \\
\text { washing cycles }\end{array}$} & \multicolumn{2}{|c|}{ Inhibition zone $(\mathrm{mm})$} \\
\hline & & S. aureus & E. coli \\
\hline 0 & 0 & 13 & 12 \\
\hline 15 & 0 & 17 & 15 \\
\hline 30 & 0 & 22 & 21 \\
\hline 60 & 0 & 22 & 22 \\
\hline 0 & 1 & 8 & 8 \\
\hline 15 & 1 & 12 & 13 \\
\hline 30 & 1 & 15 & 14.5 \\
\hline 60 & 1 & 15 & 14 \\
\hline 0 & 3 & 5 & 0 \\
\hline 15 & 3 & 0 & 0 \\
\hline 30 & 3 & 7 & 5 \\
\hline 60 & 3 & 7 & 6 \\
\hline 0 & 5 & 0 & 0 \\
\hline 15 & 5 & 0 & 0 \\
\hline 30 & 5 & 1.5 & 2 \\
\hline 60 & 5 & 1.5 & 2 \\
\hline 0 & 7 & 0 & 0 \\
\hline 15 & 7 & 0 & 0 \\
\hline 30 & 7 & 0 & 0 \\
\hline 60 & 7 & 0 & 0 \\
\hline 0 & 10 & 0 & 0 \\
\hline 15 & 10 & 0 & 0 \\
\hline 30 & 10 & 0 & 0 \\
\hline 60 & 10 & 0 & 0 \\
\hline 0 & 15 & 0 & 0 \\
\hline 15 & 15 & 0 & 0 \\
\hline 30 & 15 & 0 & 0 \\
\hline 60 & 15 & 0 & 0 \\
\hline 0 & 20 & 0 & 0 \\
\hline 15 & 20 & 0 & 0 \\
\hline 30 & 20 & 0 & 0 \\
\hline 60 & 20 & 0 & 0 \\
\hline
\end{tabular}

of 10 and $15 \mathrm{~g} / \mathrm{L}$ the antibacterial performance of the finished fabrics showed inhibition zones of $1 \mathrm{~mm}, 4 \mathrm{~mm}, 0.5 \mathrm{~mm}$, and $3 \mathrm{~mm}$ for $S$. aureus and $E$. coli, respectively, compared with zero inhibition zone in absence of MDA up to 7 th washing cycle. After the 7th washing cycle, both in presence and in absence of MDA, the finished fabrics showed zero inhibition zones. These findings mean that incorporation of MDA enhances the antibacterial performance of the finished fabrics. This is certainly due to the generation of crosslinks from both PI radicals and poly-MDA at the same time. 
TABLE 2: Effect of MDA concentration on the inhibition zone ( $\mathrm{mm}$ ) of S. aureus and E. coli. Synthesis conditions: DS $=0.2 ;[C M S], 10 \mathrm{~g} / \mathrm{L}$; [PI], $1 \mathrm{~g} / \mathrm{L} ;\left[\mathrm{AgNO}_{3}\right], 1 \mathrm{~g} / \mathrm{L}$; temperature, $40^{\circ} \mathrm{C}$; time, $60 \mathrm{~min} ; \mathrm{M}: \mathrm{L}$ ratio, $1: 20 ; \mathrm{pH}$, 7. Finishing conditions: pad-dry-photocure, AgNPs colloidal solution, and [MDA], 5, 10, and $15 \mathrm{~g} / \mathrm{L}$. Curing conditions: drying for $5 \mathrm{~min}$ at $100^{\circ} \mathrm{C}$; UV curing for $60 \mathrm{~min}$. Washing conditions: Egyptol, $2 \mathrm{~g} / \mathrm{L}$; fabric : liquor ratio, $1: 10$; temperature, $50^{\circ} \mathrm{C}$ for $10 \mathrm{~min}$.

\begin{tabular}{|c|c|c|c|}
\hline \multirow{2}{*}{$\begin{array}{l}\text { [MDA] } \\
(\mathrm{g} / \mathrm{L})\end{array}$} & \multirow{2}{*}{$\begin{array}{c}\text { Number of } \\
\text { washing cycles }\end{array}$} & \multicolumn{2}{|c|}{ Inhibition zone (mm) } \\
\hline & & S. aureus & E. coli \\
\hline 0 & 0 & 21 & 20 \\
\hline 5 & 0 & 21 & 21 \\
\hline 10 & 0 & 23 & 23 \\
\hline 15 & 0 & 24 & 23 \\
\hline 0 & 1 & 20 & 20 \\
\hline 5 & 1 & 20 & 18 \\
\hline 10 & 1 & 22 & 19 \\
\hline 15 & 1 & 24 & 22 \\
\hline 0 & 3 & 14 & 14 \\
\hline 5 & 3 & 7 & 8 \\
\hline 10 & 3 & 14 & 13 \\
\hline 15 & 3 & 15 & 14 \\
\hline 0 & 5 & 0 & 0 \\
\hline 5 & 5 & 0 & 0 \\
\hline 10 & 5 & 4 & 3 \\
\hline 15 & 5 & 4 & 2 \\
\hline 0 & 7 & 0.5 & 0 \\
\hline 5 & 7 & 0 & 0 \\
\hline 10 & 7 & 1.0 & 0.5 \\
\hline 15 & 7 & 4.0 & 3.0 \\
\hline 0 & 10 & 0 & 0 \\
\hline 5 & 10 & 0 & 0 \\
\hline 10 & 10 & 0 & 0 \\
\hline 15 & 10 & 0 & 0 \\
\hline 0 & 15 & 0 & 0 \\
\hline 5 & 15 & 0 & 0 \\
\hline 10 & 15 & 0 & 0 \\
\hline 15 & 15 & 0 & 0 \\
\hline 0 & 20 & 0 & 0 \\
\hline 5 & 20 & 0 & 0 \\
\hline 10 & 20 & 0 & 0 \\
\hline 15 & 20 & 0 & 0 \\
\hline
\end{tabular}

\section{Conclusions}

4-(Trimethyl ammoniummethyl) benzophenone chloride (a water soluble photoinitiator), PI/UV system, carboxymethyl starch, (a water soluble ecofriendly polymer), and water (a solvent) were used to synthesis AgNPs using silver nitrate as a precursor. Thus, the chemicals and the process are totally green. The reduction of $\mathrm{Ag}^{+}$to $\mathrm{Ag}^{0}$ was successfully achieved using CMS, PI, and $\mathrm{AgNO}_{3}$ concentrations of $10 \mathrm{~g} / \mathrm{L}, 1 \mathrm{~g} / \mathrm{L}$, and $1 \mathrm{~g} / \mathrm{L}$, respectively, at $40^{\circ} \mathrm{C}$ for $60 \mathrm{~min}$ at $\mathrm{pH} ; 7$ using a $\mathrm{M}: \mathrm{L}$ ratio of 1:20. AgNPs so obtained have round shape morphology. The sizes of synthesized AgNPs were found in the range of $1-7 \mathrm{~nm}$ and the highest counts\% of these particles was for particles of $1 \mathrm{~nm}$. Incorporation of MDA enhances the antibacterial performance of AgNPs finished fabrics. The antibacterial performance is directly proportional to the irradiation time and the concentration of MDA but inversely proportional to the number of washing cycles. The inhibition zone for Gram +ve bacteria and Gram -ve is the same although they are different in the cell wall structure and mode of action due to the nanosize structure formed.

\section{Conflict of Interests}

The authors declare that they have no conflict of interests regarding the publication of this paper.

\section{References}

[1] W. Chen, W. Cai, L. Zhang, G. Wang, and L. Zhang, "Sonochemical processes and formation of gold nanoparticles within pores of mesoporous silica," Journal of Colloid and Interface Science, vol. 238, no. 2, pp. 291-295, 2001.

[2] A. Frattini, N. Pellegri, D. Nicastro, and O. de Sanctis, "Effect of amine groups in the synthesis of Ag nanoparticles using aminosilanes," Materials Chemistry and Physics, vol. 94, no. 1, pp. 148-152, 2005.

[3] A. A. Hebeish, M. H. El-Rafie, F. A. Abdel-Mohdy, E. S. AbdelHalim, and H. E. Emam, "Carboxymethyl cellulose for green synthesis and stabilization of silver nanoparticles," Carbohydrate Polymers, vol. 82, no. 3, pp. 933-941, 2010.

[4] V. K. Sharma, R. A. Yngard, and Y. Lin, "Silver nanoparticles: Green synthesis and their antimicrobial activities," Advances in Colloid and Interface Science, vol. 145, no. 1-2, pp. 83-96, 2009.

[5] A. Hebeish, A. El-Shafei, S. Sharaf, and S. Zaghloul, "Novel precursors for green synthesis and application of silver nanoparticles in the realm of cotton finishing," Carbohydrate Polymers, vol. 84, no. 1, pp. 605-613, 2011.

[6] A. Saxena, R. M. Tripathi, F. Zafar, and P. Singh, "Green synthesis of silver nanoparticles using aqueous solution of Ficus benghalensis leaf extract and characterization of their antibacterial activity," Materials Letters, vol. 67, no. 1, pp. 91-94, 2012.

[7] J. Chen, J. Wang, X. Zhang, and Y. Jin, "Microwave-assisted green synthesis of silver nanoparticles by carboxymethyl cellulose sodium and silver nitrate," Materials Chemistry and Physics, vol. 108, no. 2-3, pp. 421-424, 2008.

[8] M. Sathishkumar, K. Sneha, S. W. Won, C.-W. Cho, S. Kim, and Y.-S. Yun, "Cinnamon zeylanicum bark extract and powder mediated green synthesis of nano-crystalline silver particles and its bactericidal activity," Colloids and Surfaces B: Biointerfaces, vol. 73, no. 2, pp. 332-338, 2009.

[9] E. S. Abdel-Halim, M. H. El-Rafie, and S. S. Al-Deyab, "Polyacrylamide/guar gum graft copolymer for preparation of silver nanoparticles," Carbohydrate Polymers, vol. 85, no. 3, pp. 692697, 2011.

[10] M. H. El-Rafie, T. I. Shaheen, A. A. Mohamed, and A. Hebeish, "Bio-synthesis and applications of silver nanoparticles onto cotton fabrics," Carbohydrate Polymers, vol. 90, no. 2, pp. 915920, 2012. 
[11] P. Vankar and D. Shukla, "Biosynthesis of silver nanoparticles using lemon leaves extract and its application for antimicrobial finish on fabric," Applied Nanoscience, vol. 2, no. 2, pp. 163-168, 2012.

[12] N. Vigneshwaran, R. P. Nachane, R. H. Balasubramanya, and P. V. Varadarajan, "A novel one-pot 'green' synthesis of stable silver nanoparticles using soluble starch," Carbohydrate Research, vol. 341, no. 12, pp. 2012-2018, 2006.

[13] K. Vijayaraghavan, S. P. K. Nalini, N. U. Prakash, and D. Madhankumar, "One step green synthesis of silver nano/microparticles using extracts of Trachyspermum ammi and Papaver somniferum," Colloids and Surfaces B: Biointerfaces, vol. 94, pp. 114-117, 2012.

[14] Y. Yagci, M. Sangermano, and G. Rizza, "A visible light photochemical route to silver-epoxy nanocomposites by simultaneous polymerization-reduction approach," Polymer, vol. 49, no. 24, pp. 5195-5198, 2008.

[15] Y. Yagci, O. Sahin, T. Ozturk, S. Marchi, S. Grassini, and M. Sangermano, "Synthesis of silver/epoxy nanocomposites by visible light sensitization using highly conjugated thiophene derivatives," Reactive and Functional Polymers, vol. 71, no. 8, pp. 857-862, 2011.

[16] L. Balan, J. Malval, R. Schneider, D. le Nouen, and D. Lougnot, "In-situ fabrication of polyacrylate-silver nanocomposite through photoinduced tandem reactions involving eosin dye," Polymer, vol. 51, no. 6, pp. 1363-1369, 2010.

[17] L. Keller, C. Decker, K. Zahouily, S. Benfarhi, J. M. Le Meins, and J. Miehe-Brendle, "Synthesis of polymer nanocomposites by UV-curing of organoclay-acrylic resins," Polymer, vol. 45, no. 22, pp. 7437-7447, 2004.

[18] C. Decker, L. Keller, K. Zahouily, and S. Benfarhi, "Synthesis of nanocomposite polymers by UV-radiation curing," Polymer, vol. 46, no. 17, pp. 6640-6648, 2005.

[19] L. Balan, R. Schneider, and D. J. Lougnot, "A new and convenient route to polyacrylate/silver nanocomposites by lightinduced cross-linking polymerization," Progress in Organic Coatings, vol. 62, no. 3, pp. 351-357, 2008.

[20] L. Balan, M. Jin, J. Malval, H. Chaumeil, A. Defoin, and L. Vidal, "Fabrication of silver nanoparticle-embedded polymer promoted by combined photochemical properties of a 2,7diaminofluorene derivative dye," Macromolecules, vol. 41, no. 23, pp. 9359-9365, 2008.

[21] L. Balan and D. Burget, "Synthesis of metal/polymer nanocomposite by UV-radiation curing," European Polymer Journal, vol. 42, no. 12, pp. 3180-3189, 2006.

[22] M. A. El-Sheikh, "A novel photosynthesis of carboxymethyl starch-stabilized silver nanoparticles," The Scientific World Journal, vol. 2014, Article ID 514563, 11 pages, 2014.

[23] L. Balan, J.-P. Malval, and D.-J. Lougnot, "In situ photochemically assisted synthesis of silver nanoparticles in polymer matrixes," in Silver Nanoparticles, D. P. Perez, Ed., pp. 79-92, InTech, Croatia, 2010.

[24] V. Alt, T. Bechert, P. Steinrücke et al., "An in vitro assessment of the antibacterial properties and cytotoxicity of nanoparticulate silver bone cement," Biomaterials, vol. 25, no. 18, pp. 4383-4391, 2004.

[25] M. S. A. S. Shah, M. Nag, T. Kalagara, S. Singh, and S. V. Manorama, "Silver on PEG-PU-TiO2 polymer nanocomposite films: an excellent system for antibacterial applications," Chemistry of Materials, vol. 20, no. 7, pp. 2455-2460, 2008.

[26] R. Dastjerdi, M. R. M. Mojtahedi, A. M. Shoshtari, and A. Khosroshahi, "Investigating the production and properties of $\mathrm{Ag} / \mathrm{TiO}_{2} / \mathrm{PP}$ antibacterial nanocomposite filament yarns," Journal of the Textile Institute, vol. 101, no. 3, pp. 204-213, 2010.

[27] X. Jia, X. Ma, D. Wei, J. Dong, and W. Qian, "Direct formation of silver nanoparticles in cuttlebone-derived organic matrix for catalytic applications," Colloids and Surfaces A: Physicochemical and Engineering Aspects, vol. 330, no. 2-3, pp. 234-240, 2008.

[28] S. Y. Yang and J. Y. Seo, "Cellular interactions on nanostructured polyelectrolyte multilayers," Colloids and Surfaces A: Physicochemical and Engineering Aspects, vol. 313-314, pp. 526529, 2008.

[29] N. Durán, P. D. Marcato, G. I. H. De Souza, O. L. Alves, and E. Esposito, "Antibacterial effect of silver nanoparticles produced by fungal process on textile fabrics and their effluent treatment," Journal of Biomedical Nanotechnology, vol. 3, no. 2, pp. 203-208, 2007.

[30] Q. Cheng, C. Li, V. Pavlinek, P. Saha, and H. Wang, "Surfacemodified antibacterial $\mathrm{TiO}_{2} / \mathrm{Ag}^{+}$nanoparticles: preparation and properties," Applied Surface Science, vol. 252, no. 12, pp. 4154-4160, 2006.

[31] S. H. Jeong, S. Y. Yeo, and S. C. Yi, “The effect of filler particle size on the antibacterial properties of compounded polymer/silver fibers," Journal of Materials Science, vol. 40, no. 20, pp. 54075411, 2005.

[32] S. T. Dubas, P. Kumlangdudsana, and P. Potiyaraj, "Layerby-layer deposition of antimicrobial silver nanoparticles on textile fibers," Colloids and Surfaces A: Physicochemical and Engineering Aspects, vol. 289, no. 1-3, pp. 105-109, 2006.

[33] R. Dastjerdi, M. R. M. Mojtahedi, and A. M. Shoshtari, "Comparing the effect of three processing methods for modification of filament yarns with inorganic nanocomposite filler and their bioactivity against staphylococcus aureus," Macromolecular Research, vol. 17, no. 6, pp. 378-387, 2009.

[34] S. Y. Yeo and S. H. Jeong, "Preparation and characterization of polypropylene/silver nanocomposite fibers," Polymer International, vol. 52, no. 7, pp. 1053-1057, 2003.

[35] A. R. Horrocks and S. C. Anand, Handbook of Technical Textiles, Woodhead Publishing Limited, the Textile Institute, Cambridge, UK, 2000.

[36] Y. Gao and R. Cranston, "Recent advances in antimicrobial treatments of textiles," Textile Research Journal, vol. 78, no. 1, pp. 60-72, 2008.

[37] M. Gorenšek and P. Recelj, "Nanosilver functionalized cotton fabric," Textile Research Journal, vol. 77, no. 3, pp. 138-141, 2007.

[38] E. Falletta, M. Bonini, E. Fratini et al., pp. 412-414, Santa Clara, Calif, USA, 2007.

[39] Y. A. Son, B. S. Kim, K. Ravikumar, and S. G. Lee, "Imparting durable antimicrobial properties to cotton fabrics using quaternary ammonium salts through 4-aminobenzenesulfonic acidchloro-triazine adduct," European Polymer Journal, vol. 42, no. 11, pp. 3059-3067, 2006.

[40] S. Lim and S. M. Hudson, "Application of a fiber-reactive chitosan derivative to cotton fabric as an antimicrobial textile finish," Carbohydrate Polymers, vol. 56, no. 2, pp. 227-234, 2004.

[41] W. K. Son, J. H. Youk, and W. H. Park, "Antimicrobial cellulose acetate nanofibers containing silver nanoparticles," Carbohydrate Polymers, vol. 65, no. 4, pp. 430-434, 2006.

[42] T. Textor, M. M. G. Fouda, and B. Mahltig, "Deposition of durable thin silver layers onto polyamides employing a heterogeneous Tollens' reaction," Applied Surface Science, vol. 256, no. 8, pp. 2337-2342, 2010. 
[43] M. Montazer, F. Alimohammadi, A. Shamei, and M. K. Rahimi, "In situ synthesis of nano silver on cotton using Tollens'reagent," Carbohydrate Polymers, vol. 87, no. 2, pp. 1706-1712, 2012.

[44] M. Montazer, F. Alimohammadi, A. Shamei, and M. K. Rahimi, "Durable antibacterial and cross-linking cotton with colloidal silver nanoparticles and butane tetracarboxylic acid without yellowing," Colloids and Surfaces B: Biointerfaces, vol. 89, no. 1, pp. 196-202, 2012.

[45] M. Gouda, "Nano-zirconium oxide and nano-silver oxide/cotton gauze fabrics for antimicrobial and wound healing acceleration," Journal of Industrial Textiles, vol. 41, no. 3, pp. 222-240, 2012.

[46] V. Thomas, M. Bajpai, and S. K. Bajpai, "In situ formation of silver nanoparticles within chitosan-attached cotton fabric for antibacterial property," Journal of Industrial Textiles, vol. 40, no. 3, pp. 229-245, 2011.

[47] W. Su, S. S. Wei, S. Q. Hu, and J. X. Tang, "Antimicrobial finishing of cotton textile with nanosized silver colloids synthesized using polyethylene glycol," Journal of the Textile Institute, vol. 102, no. 2, pp. 150-156, 2011.

[48] S. Ghosh, A. Upadhay, A. Kr.Singh, and A. Kumar, "Investigation of antimicrobial activity of silver nano particle loaded cotton fabrics which may promote wound healing," International Journal of Pharma and Bio Sciences, vol. 1, no. 3, article 32, 2010.

[49] M. H. El-Rafie, A. A. Mohamed, T. I. Shaheen, and A. Hebeish, "Antimicrobial effect of silver nanoparticles produced by fungal process on cotton fabrics," Carbohydrate Polymers, vol. 80, no. 3, pp. 779-782, 2010.

[50] A. I. Wasif and S. K. Laga, "Use of nano silver as an antimicrobial agent for cotton," Autex Research Journal, vol. 9, no. 1, pp. 5-13, 2009.

[51] M. P. Sathianarayanan and N. V. Bhat, "Durable antibacterial finishing of cotton fabrics using silver nanoparticles," BTRA Scan, vol. 39, no. 3, pp. 9-16, 2009.

[52] M. Parthiban and G. Thilagavathi, "Effect of nano silver application on microbe resistance of cotton, $\mathrm{P} / \mathrm{C}$ and lycra blended fabrics," Colourage, vol. 57, no. 4, pp. 40-44, 2009.

[53] G. Li, B. Peng, L. Chai, L. Liu, and Y. Liu, pp. 3-6, San Francisco, Calif, USA, 2009.

[54] M. S. Khalil-Abad, M. E. Yazdanshenas, and M. R. Nateghi, "Effect of cationization on adsorption of silver nanoparticles on cotton surfaces and its antibacterial activity," Cellulose, vol. 16, no. 6, pp. 1147-1157, 2009.

[55] N. V. Ke Thanh and N. T. Phuong Phong, "Investigation of antibacterial activity of cotton fabric incorporating nano silver colloid," Journal of Physics: Conference Series, vol. 187, Article ID 012072, 2009.

[56] B. Tomšič, B. Simončič, D. Cvijn, B. Orel, M. Zorko, and A. Simončič, "Elementary nano sized silver as antibacterial agent on cotton fabric," Original Scientific Paper, vol. 51, no. 7-9, pp. 199-215, 2008.

[57] P. Gupta, M. Bajpai, and S. K. Bajpai, "Textile technology: investigation of antibacterial properties of silver nanoparticleloaded poly (acrylamide-co-itaconic acid)-grafted cotton fabric," Journal of Cotton Science, vol. 12, no. 3, pp. 280-286, 2008.

[58] N. Vigneshwaran, A. A. Kathe, P. V. Varadarajan, R. P. Nachane, and R. H. Balasubramanya, "Functional finishing of cotton fabrics using silver nanoparticles," Journal of Nanoscience and Nanotechnology, vol. 7, no. 6, pp. 1893-1897, 2007.

[59] M. Messaoud, E. Chadeau, C. Brunon et al., "Photocatalytic generation of silver nanoparticles and application to the antibacterial functionalization of textile fabrics," Journal of Photochemistry and Photobiology A: Chemistry, vol. 215, no. 2-3, pp. 147-156, 2010.

[60] N. Vigneshwaran, S. Kumar, A. A. Kathe, P. V. Varadarajan, and V. Prasad, "Functional finishing of cotton fabrics using zinc oxide-soluble starch nanocomposites," Nanotechnology, vol. 17, no. 20, pp. 5087-5095, 2006.

[61] R. Dastjerdi, M. Montazer, and S. Shahsavan, "A new method to stabilize nanoparticles on textile surfaces," Colloids and Surfaces A: Physicochemical and Engineering Aspects, vol. 345, no. 1-3, pp. 202-210, 2009.

[62] M. A. El-Sheikh, Synthesis of new polymeric materials based on water-soluble starch composites [Ph.D. thesis], Cairo University, Cairo, Egypt, 1999.

[63] M. A. El-Sheikh, "Photo grafting of acrylamide onto carboxymethyl starch-part 1: utilization of the product in easy care finishing of cotton fabric," in Proceedings of the 3rd AachenDresden International Textile Conference, pp. 1-30, Aachen, Germany, 2009.

[64] M. A. El-Sheikh, "Synthesis of poly acrylamide-gcarboxymethyl starch silver nanoparticles composite and its corresponding hydrogel," in Proceedings of the 7th AachenDresden International Textile Conference, pp. 1-43, Aachen, Germany, 2013.

[65] M. A. El-Sheikh, L. K. El-Gabry, and H. M. Ibrahim, "Photosynthesis of carboxymethyl starch-stabilized silver nanoparticles and utilization to impart antibacterial finishing for wool and acrylic fabrics," Journal of Polymers, vol. 2013, Article ID 792035, 9 pages, 2013.

[66] M. A. El-Sheikh, "Carboxymethylation of maize starch at mild conditions," Carbohydrate Polymers, vol. 79, no. 4, pp. 875-881, 2010.

[67] G. C. Daul, R. M. Reinhardt, and J. D. Reid, "Preparation of soluble yarns by the carboxymethylation of cotton," Textile Research Journal, vol. 23, no. 10, pp. 719-726, 1953.

[68] N. Y. Abou-Zeid, A. I. Waly, N. G. Kandile, A. A. Rushdy, M. A. El-Sheikh, and H. M. Ibrahim, "Preparation, characterization and antibacterial properties of cyanoethylchitosan/cellulose acetate polymer blended films," Carbohydrate Polymers, vol. 84, no. 1, pp. 223-230, 2011.

[69] CLSI, Performance Standards for Antimicrobial Disk Susceptibility Tests, Approved Standard, Clinical Laboratory Standards Institute, Wayne, Pa, USA, 9th edition, 2006.

[70] J. H. Jorgensen and J. D. Turnidge, "Susceptibility test methods: dilution and disk diffusion methods," in Manual of Clinical Microbiology, P. R. Murray, E. J. Baron, J. H. Jorgensen, M. L. Landry, and M. A. Pfaller, Eds., pp. 1152-1172, ASM Press, Washington, DC, USA, 2007.

[71] M. H. El-Rafie, M. E. El-Naggar, M. A. Ramadan, M. M. G. Fouda, S. S. Al-Deyab, and A. Hebeish, "Environmental synthesis of silver nanoparticles using hydroxypropyl starch and their characterization," Carbohydrate Polymers, vol. 86, no. 2, pp. 630-635, 2011.

[72] A. P. Kumar and R. P. Singh, "Biocomposites of cellulose reinforced starch: improvement of properties by photo-induced crosslinking," Bioresource Technology, vol. 99, no. 18, pp. 8803$8809,2008$. 

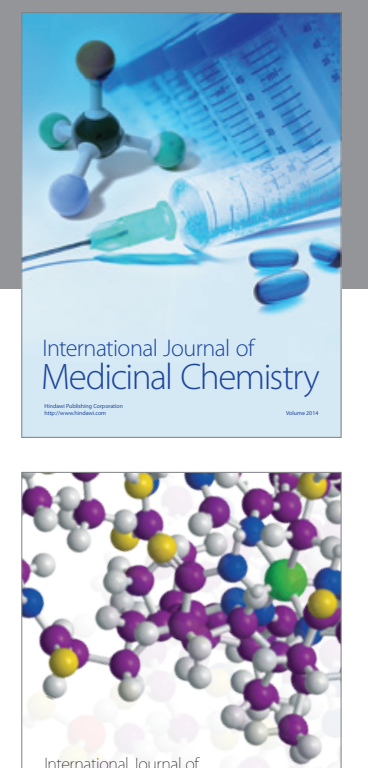

\section{Carbohydrate} Chemistry

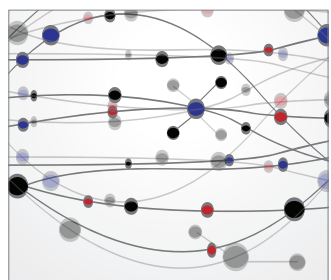

The Scientific World Journal
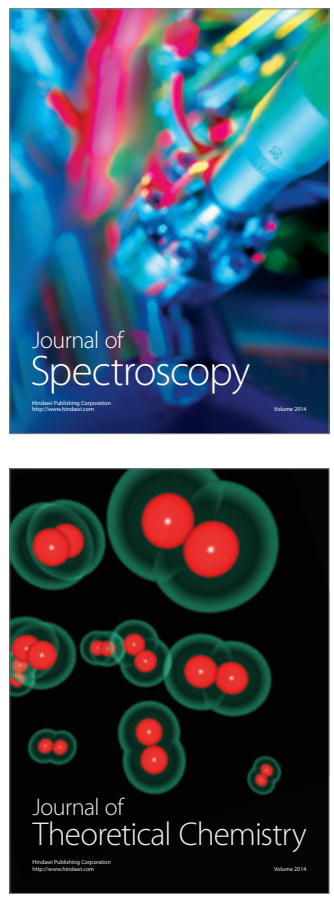
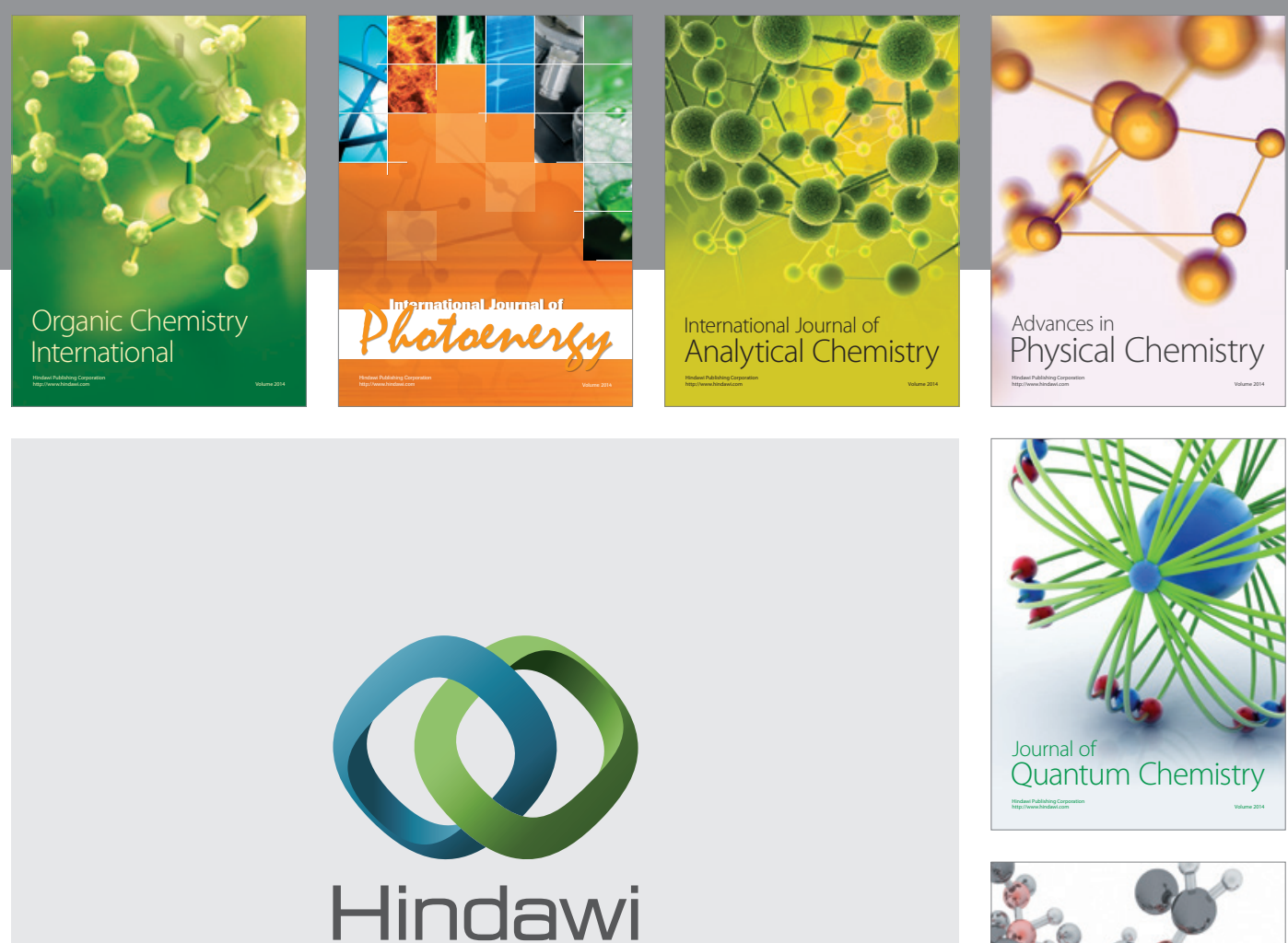

Submit your manuscripts at

http://www.hindawi.com

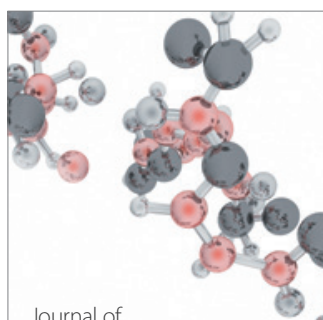

Analytical Methods

in Chemistry

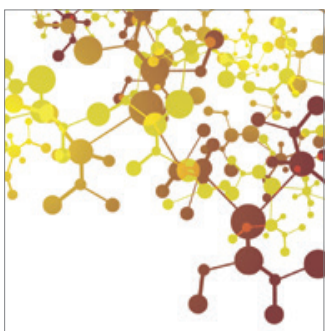

Journal of

Applied Chemistry

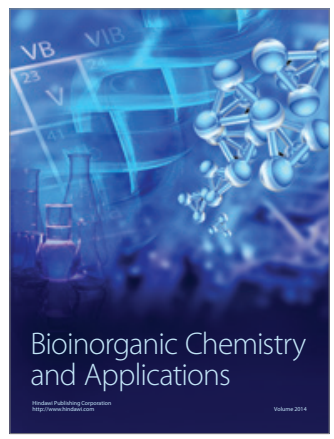

Inorganic Chemistry
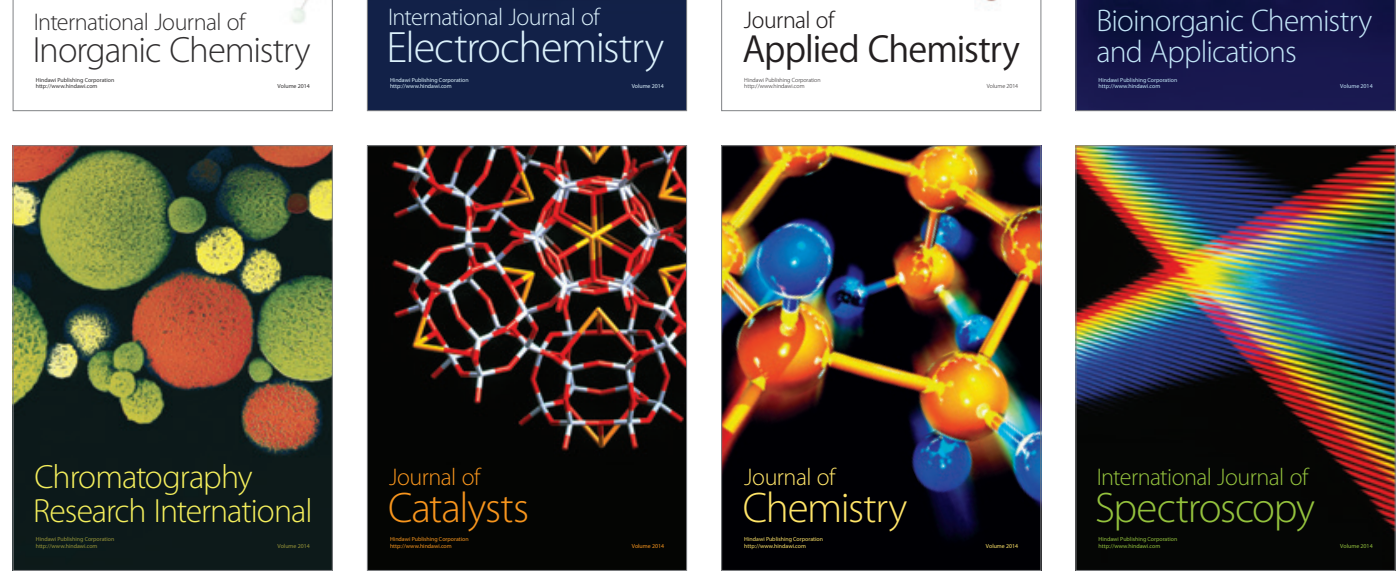